\title{
$D 2-\dot{6} /$
}

80008

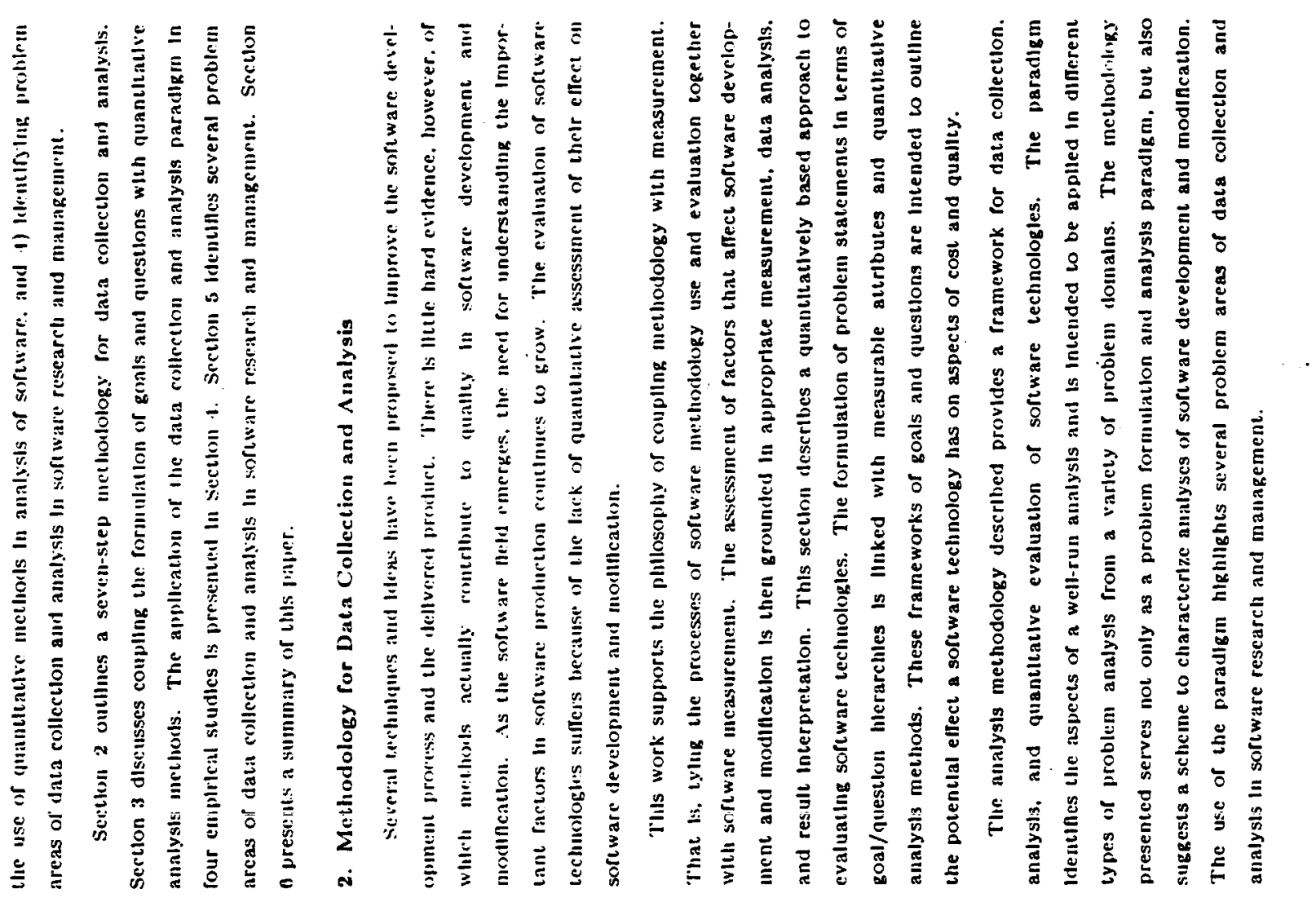

$2, r^{h}$

5
-0
0
0

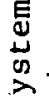

के

군

वे

ำ

过

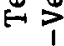

我

岂

解

चे

苛

安

殅

$\triangle 5$

ฮิ ญ

ส

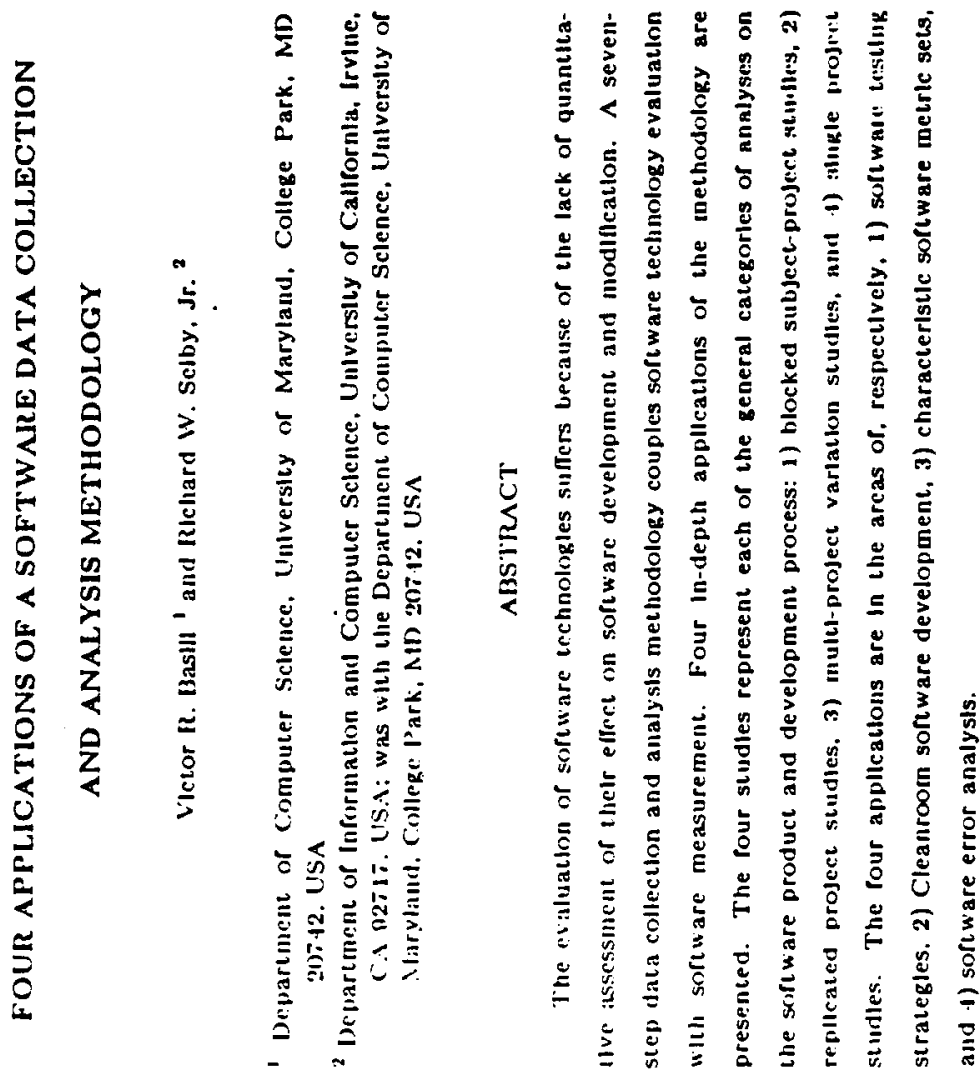

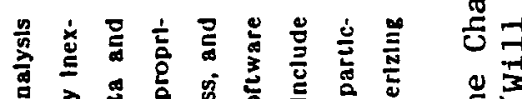

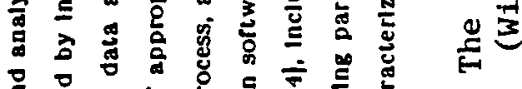

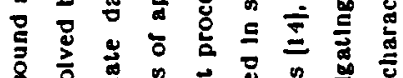

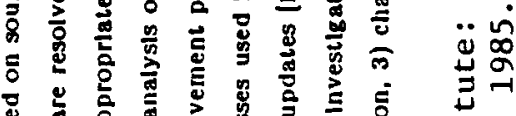

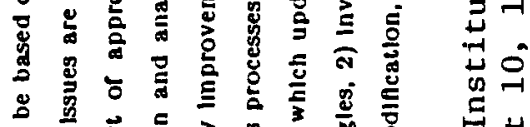

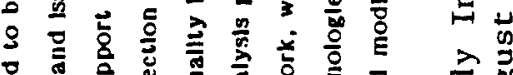

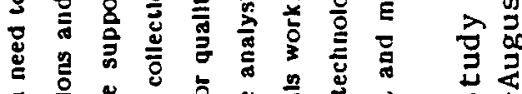

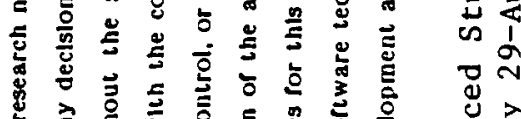

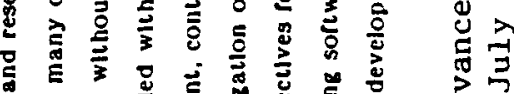

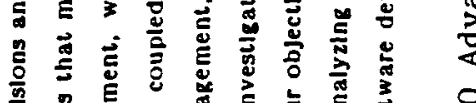

要雪

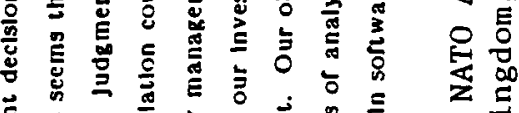

它

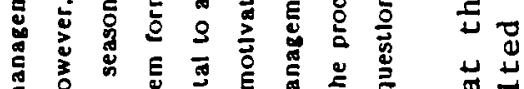

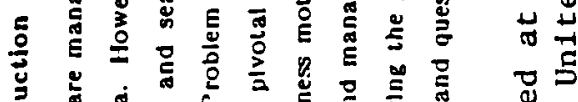

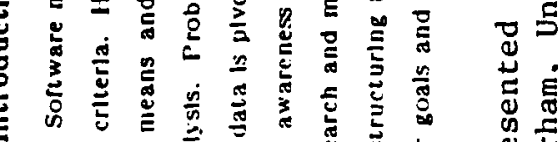

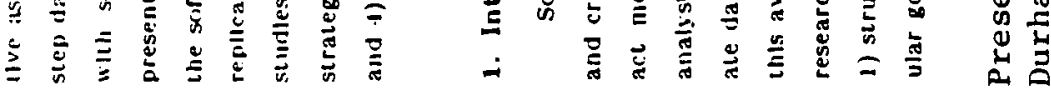



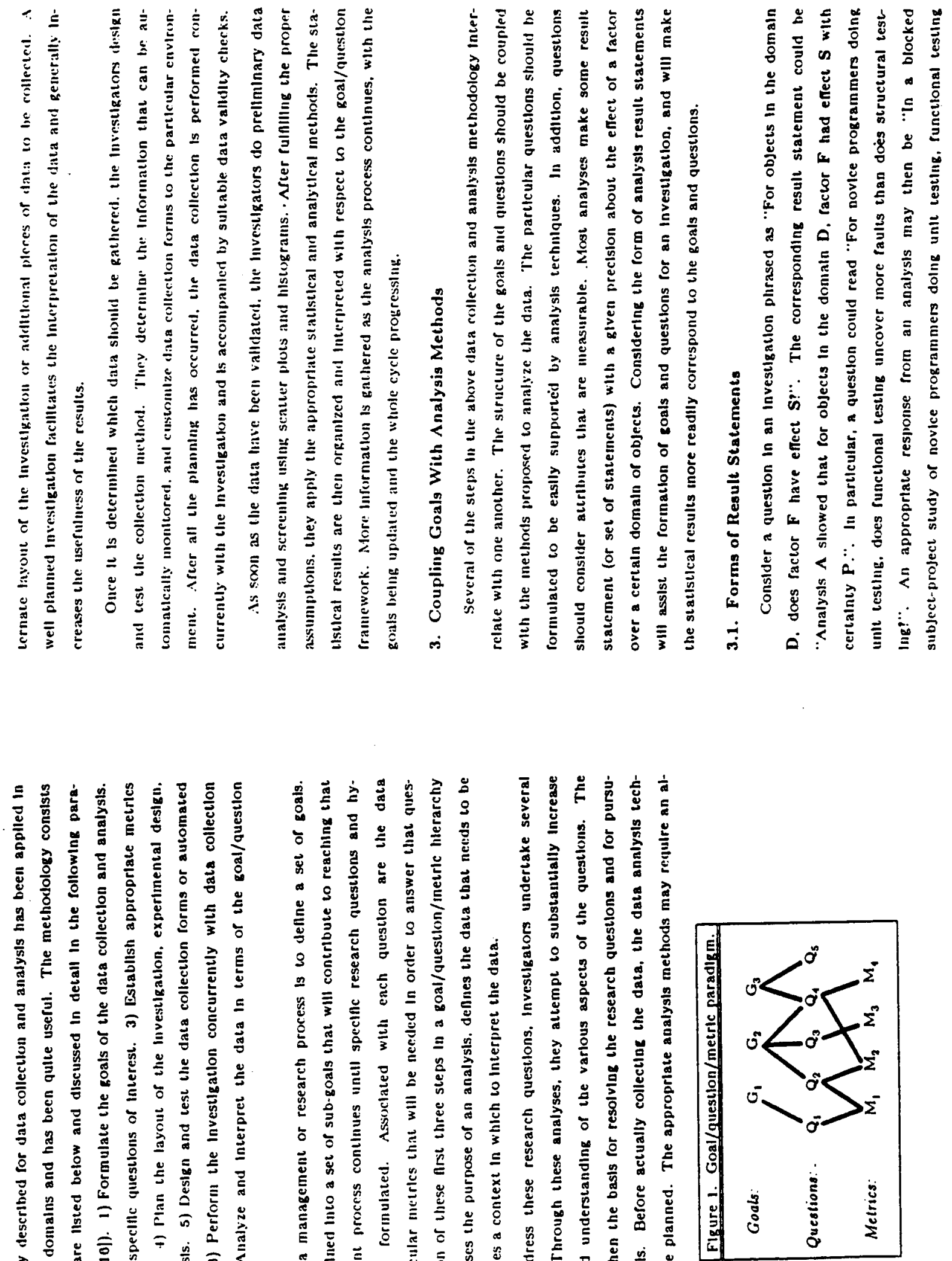

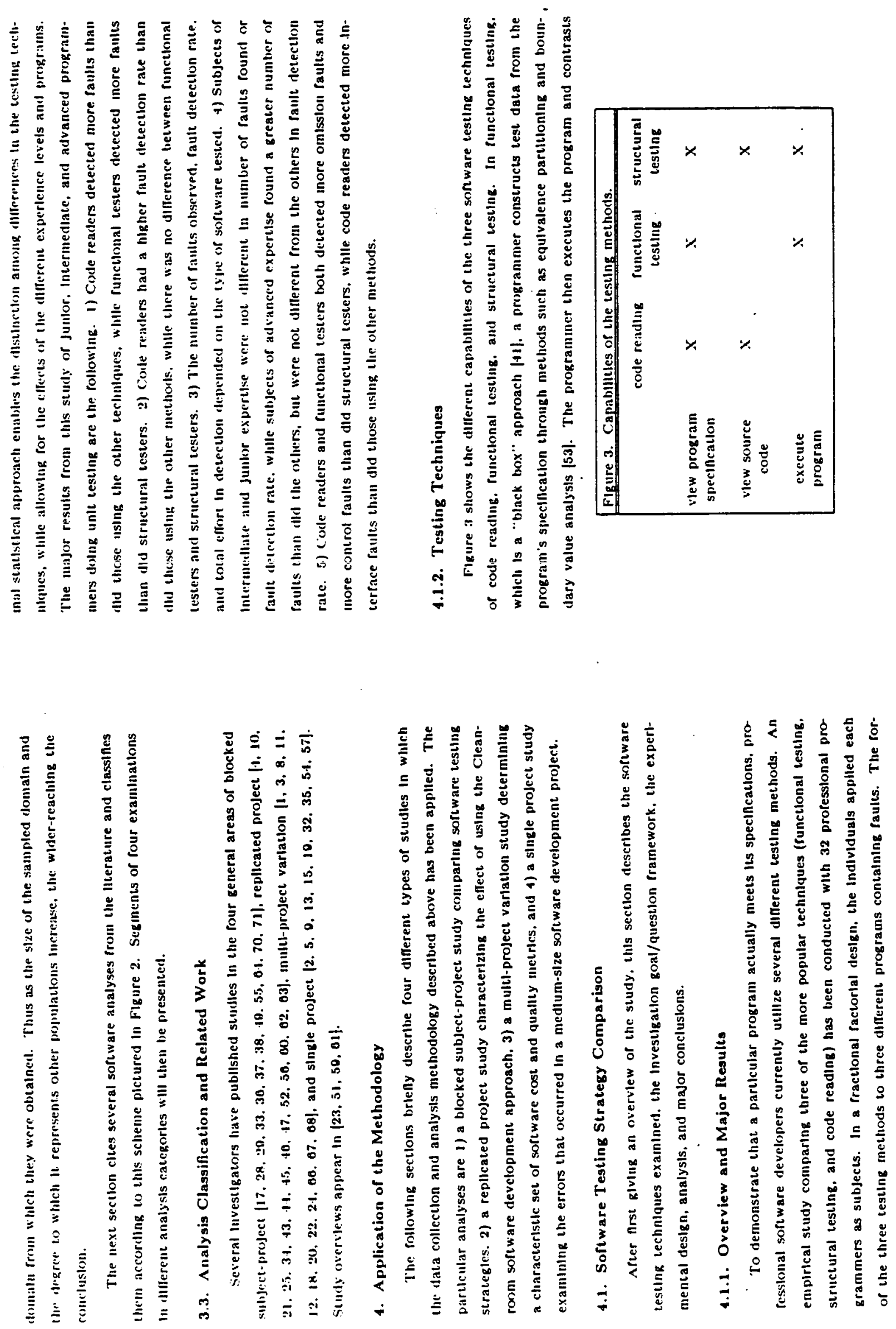


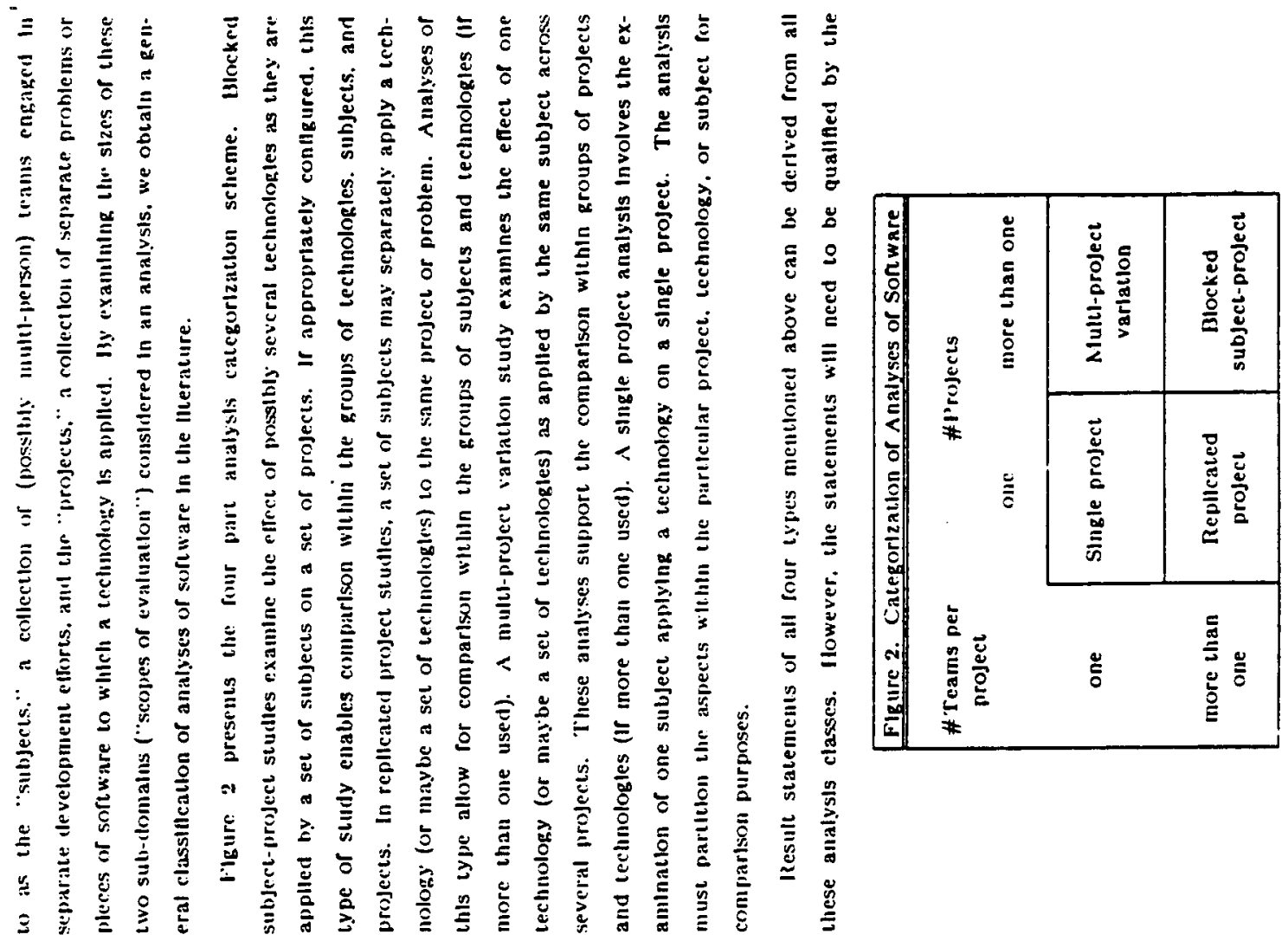
II In: W II In (1)

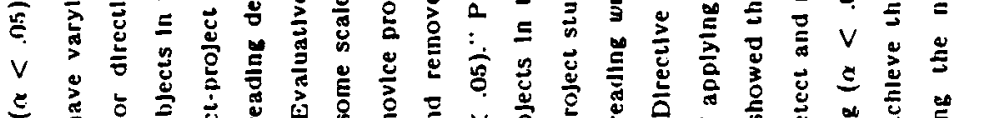
c) I औ)

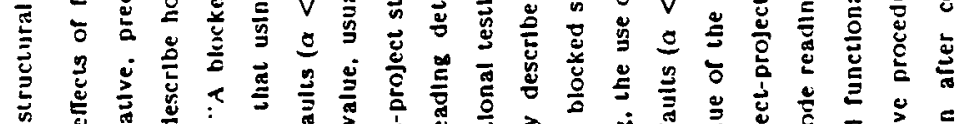
IIning (1) (1) Int Int (1) 

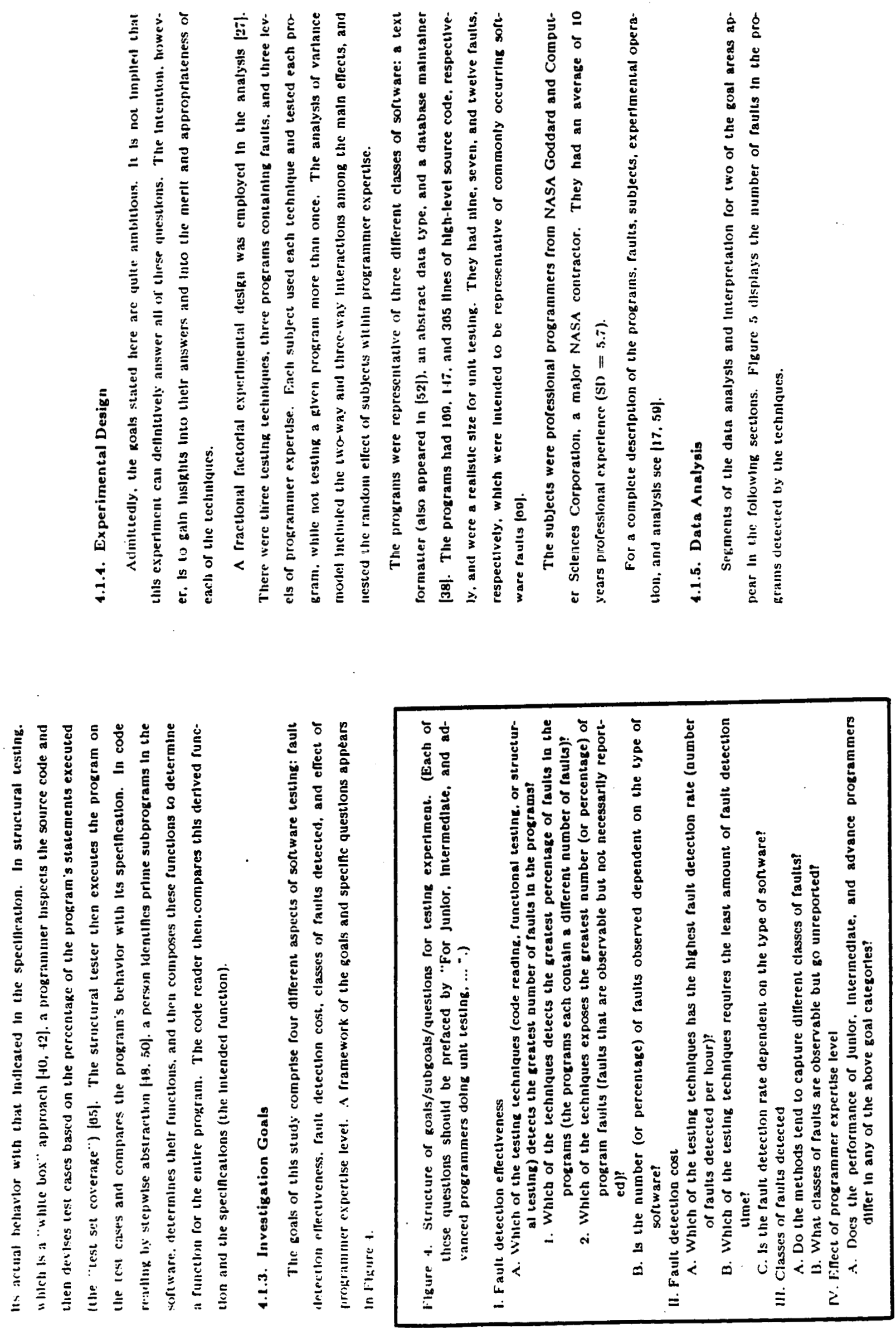

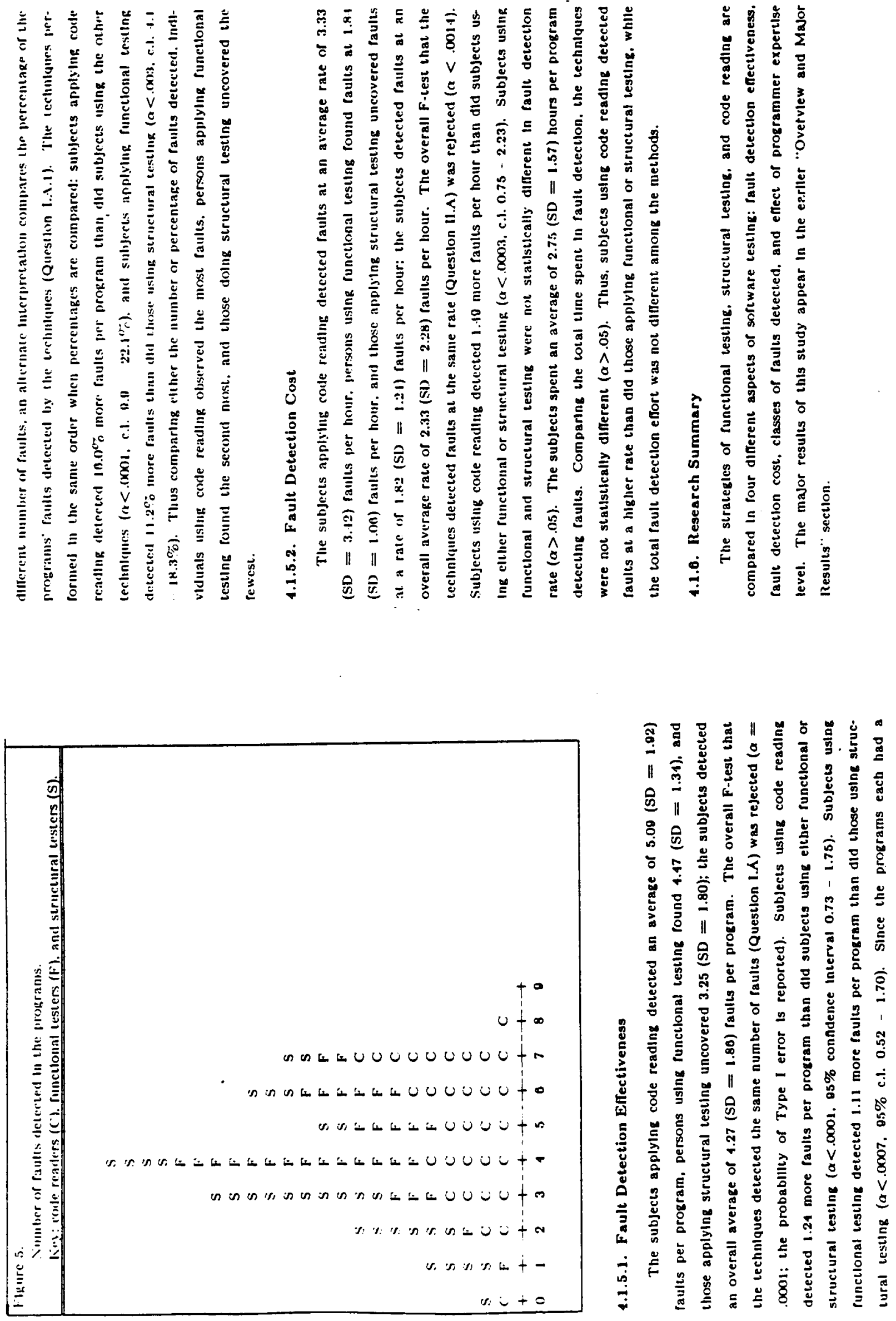

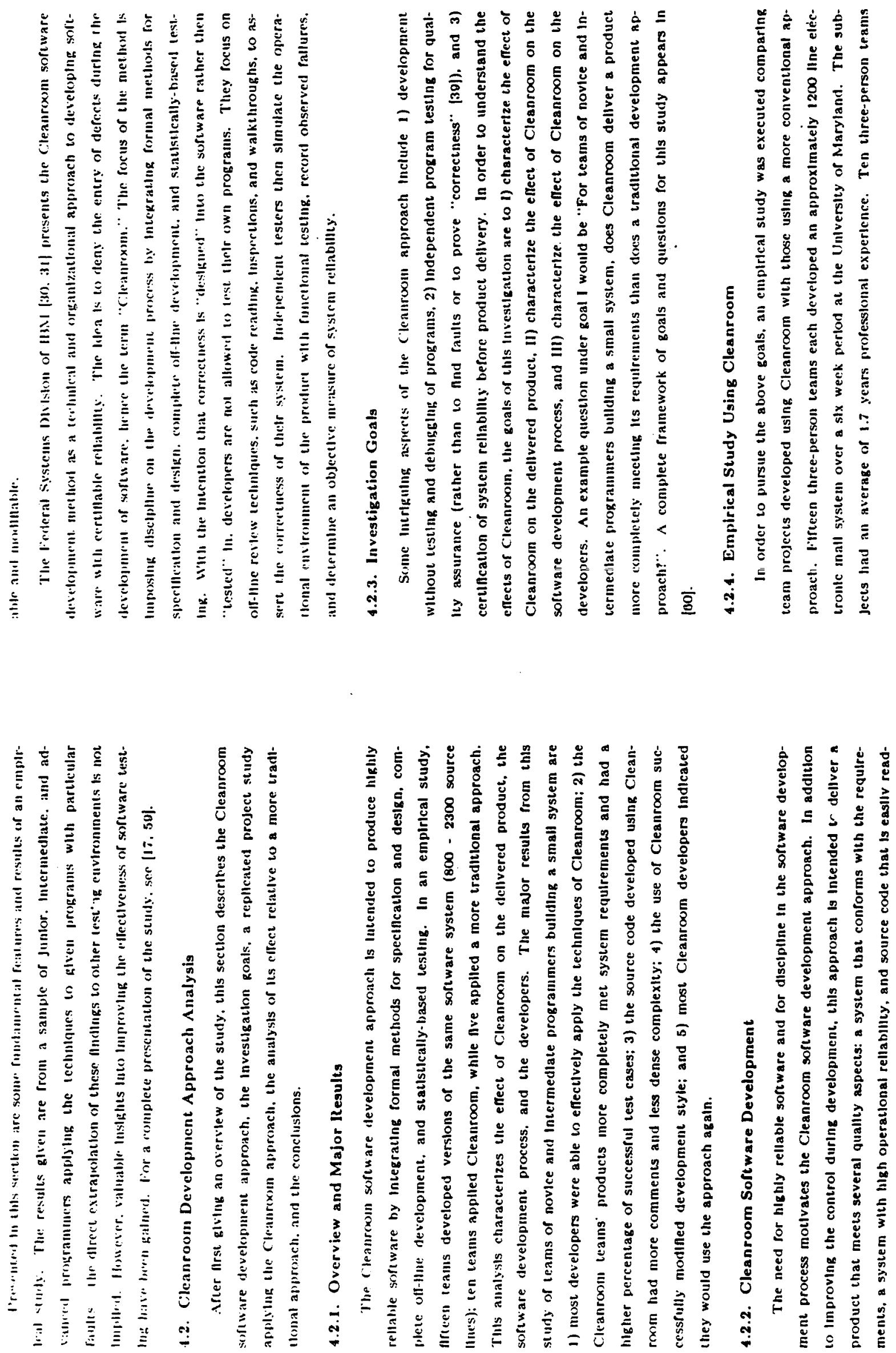

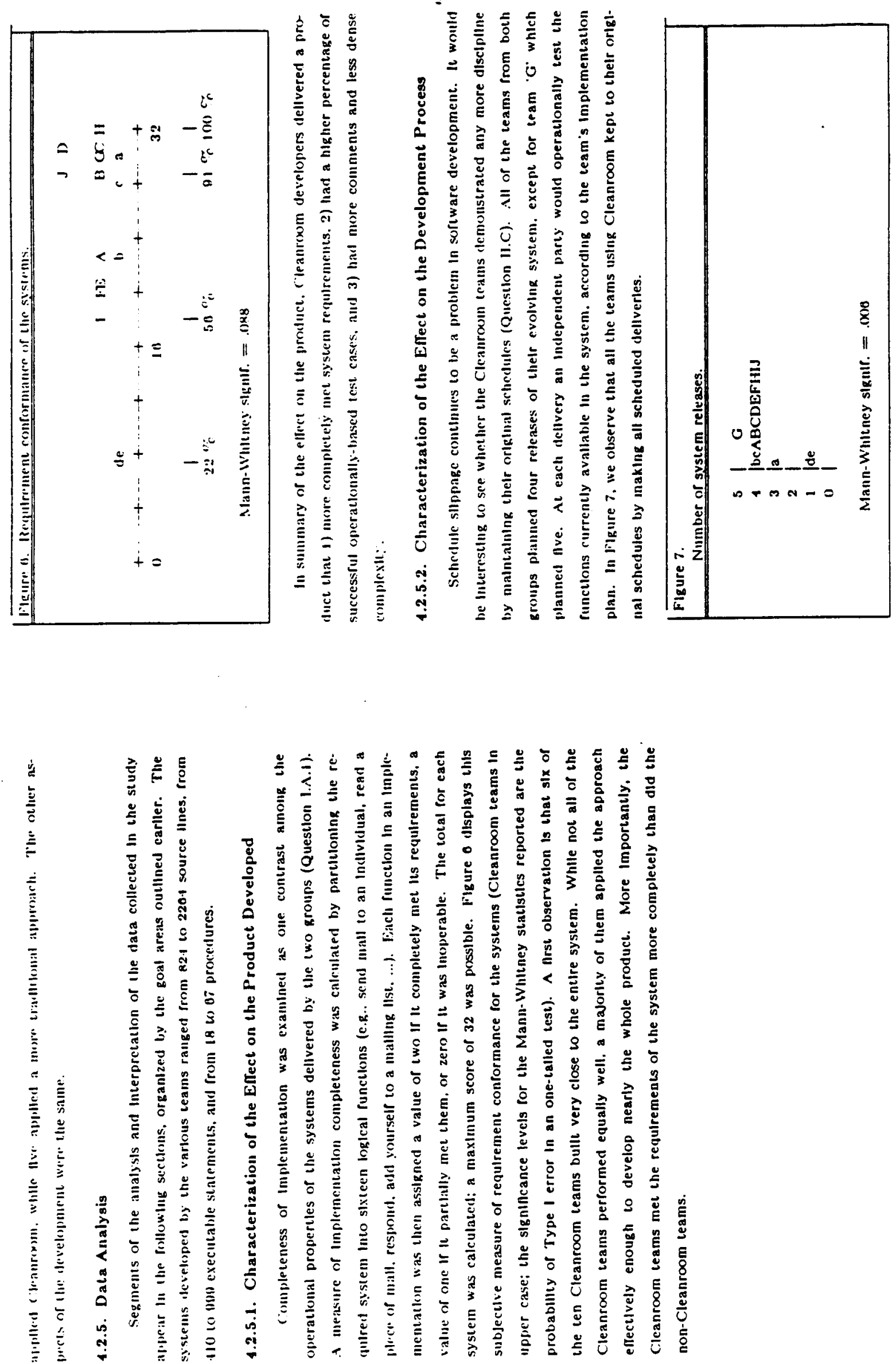

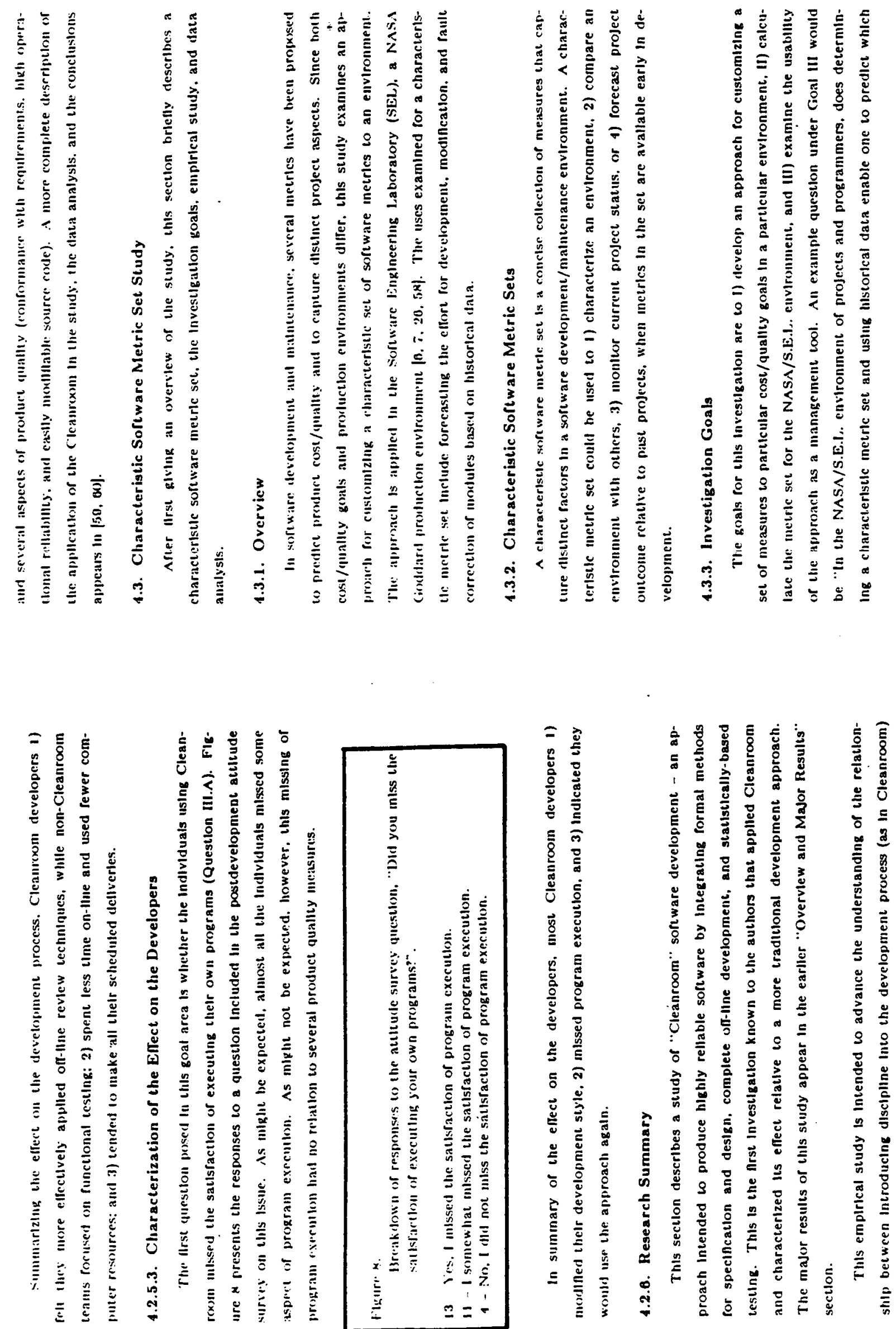

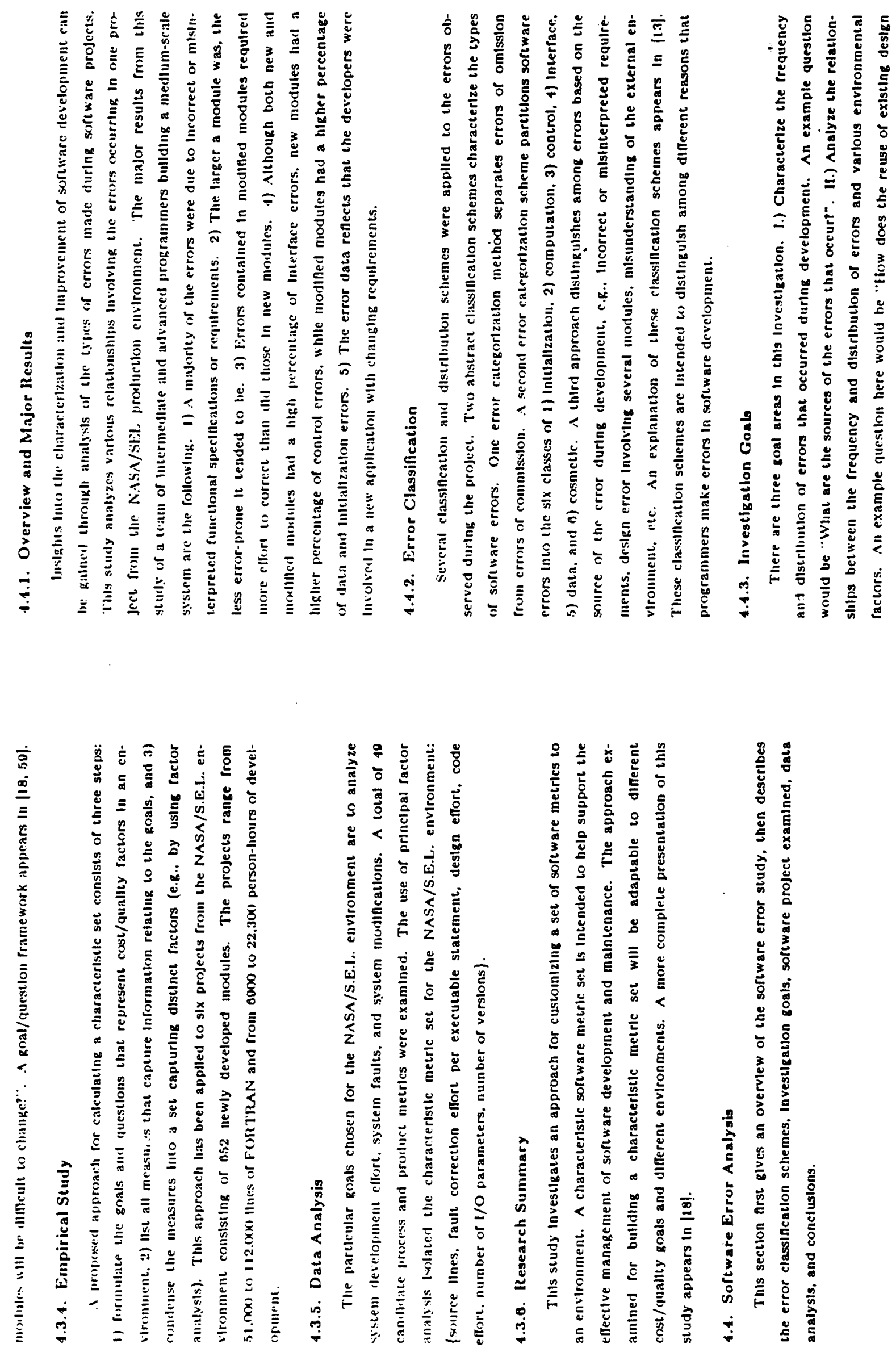

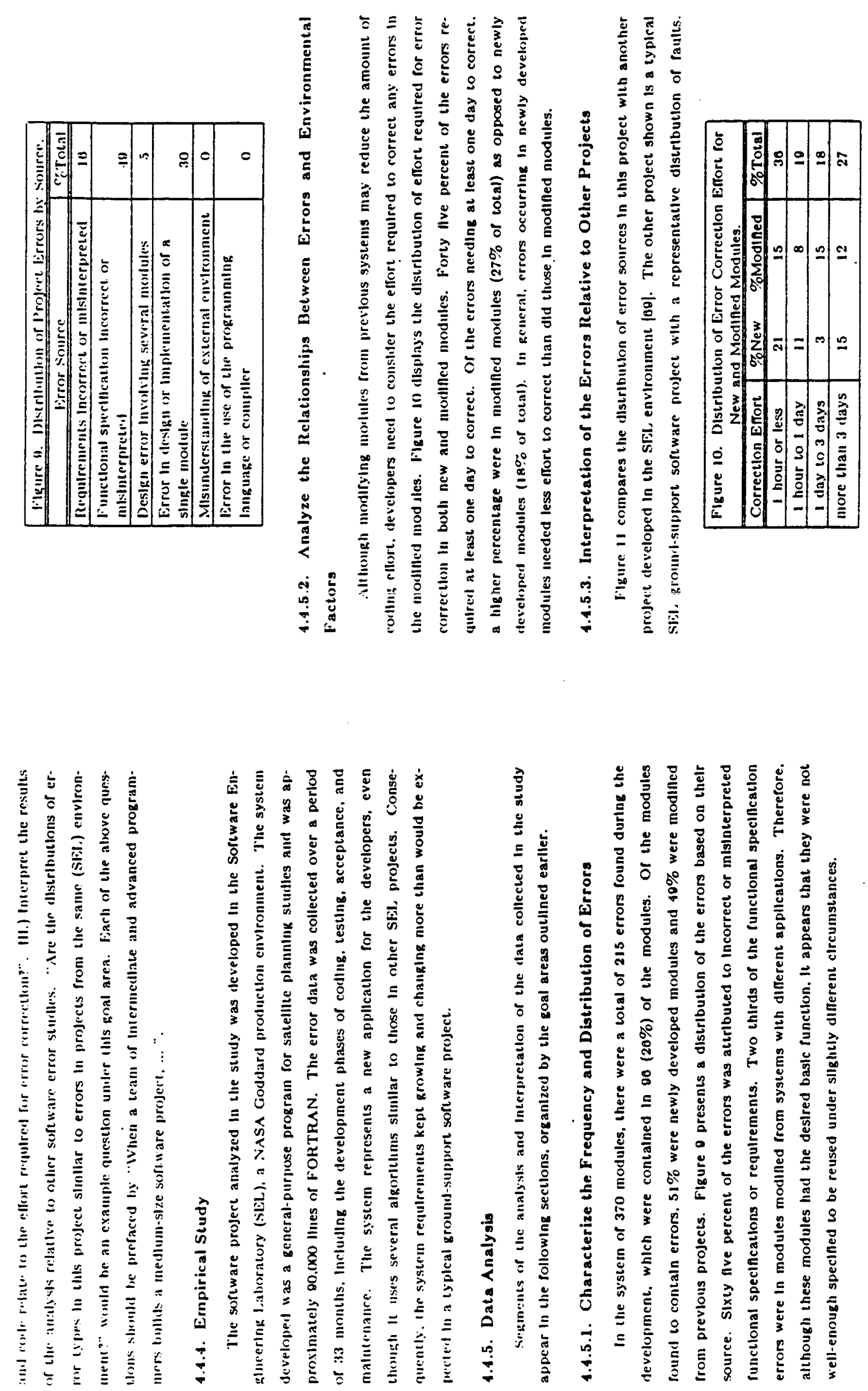

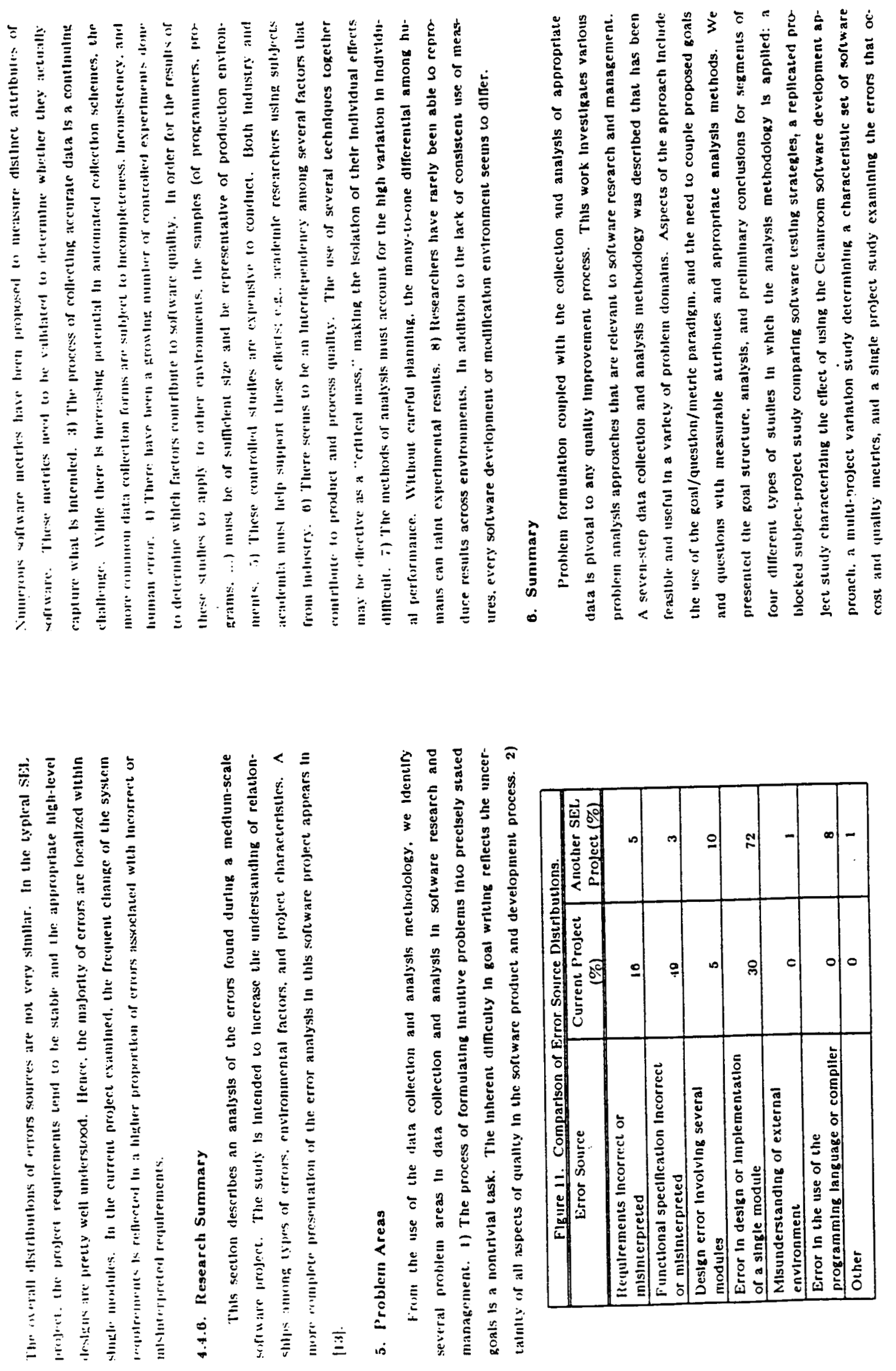

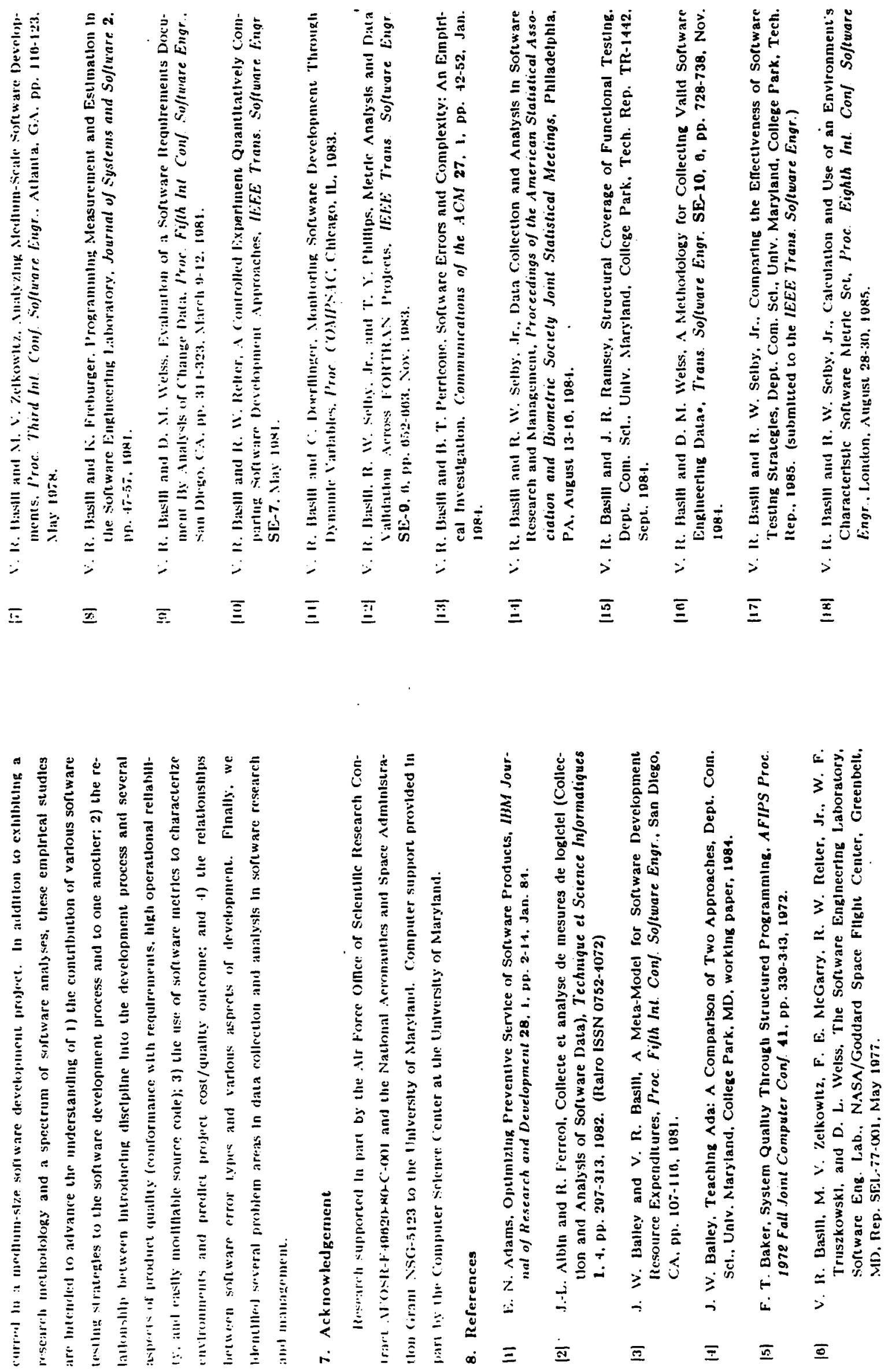
(I)

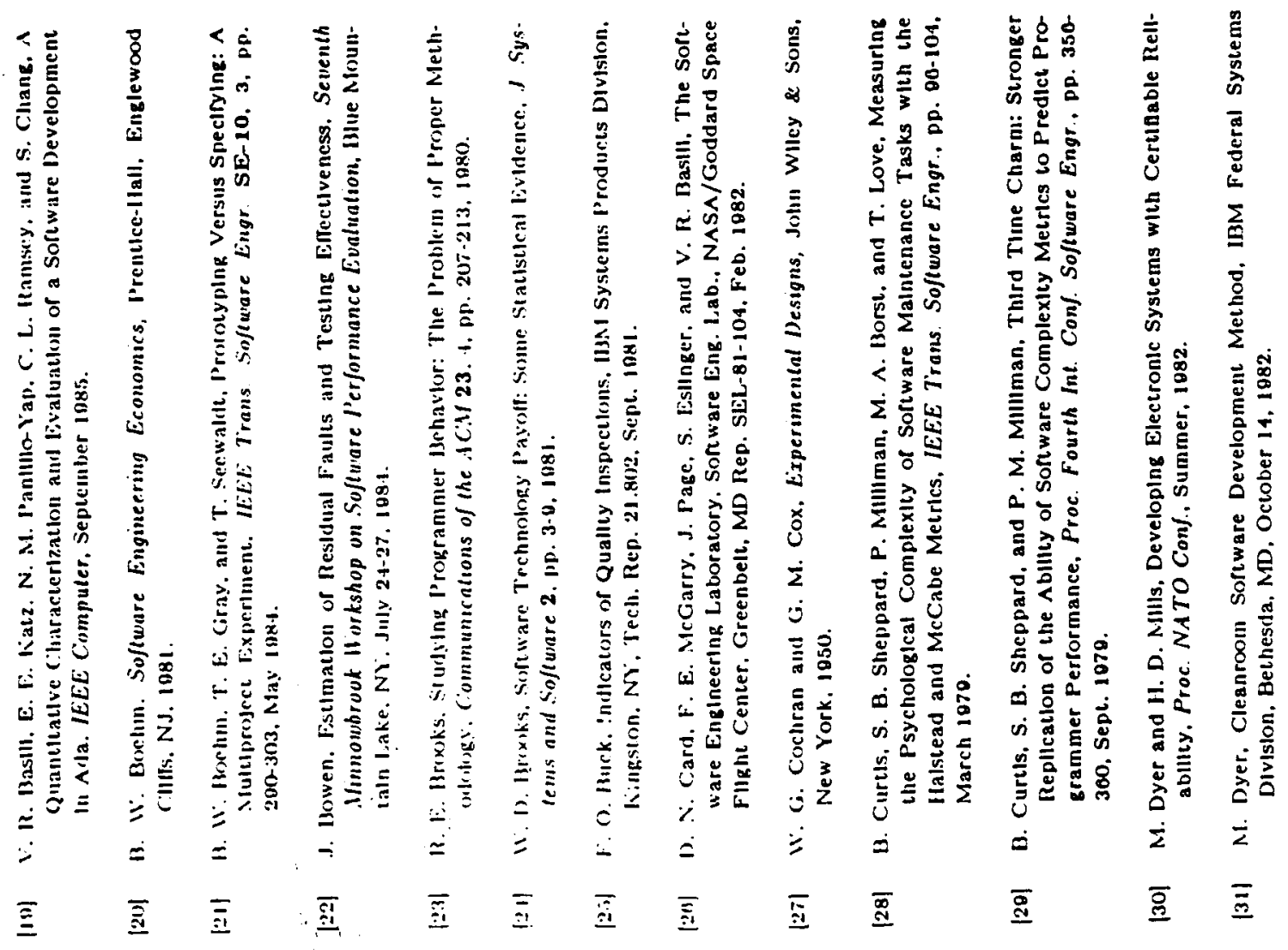

